
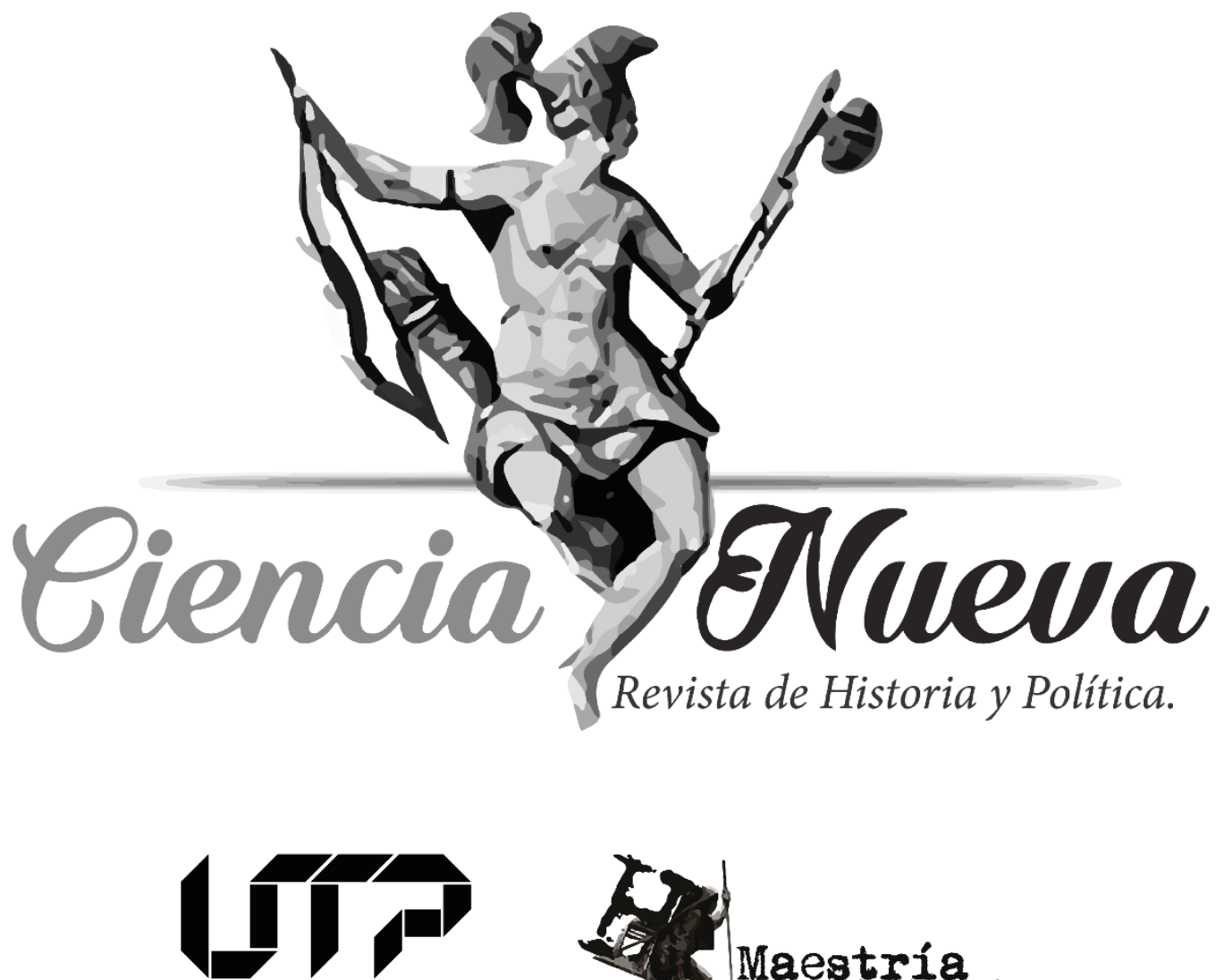

Universidad Tecnológica de Pereira

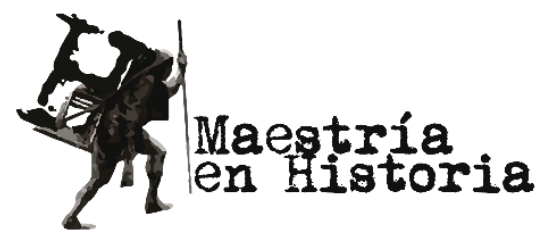

ESTUDIOS HISTÓRICOS

DE LA UNIVERSIDAD REPUBLICANA A LA UNIVERSIDAD NACIONAL DE COLOMBIA: MODERNIDAD Y CONSTRUCCIÓN DE LA REPÚBLICA EN EL SIGLO XIX (1826-1867)

FROM THE UNIVERSIDAD REPUBLICANA TO THE UNIVERSIDAD NACIONAL DE COLOMBIA: MODERNITY AND THE CONSTRUCTION OF THE REPUBLIC IN THE 19TH CENTURY (1826-1867)

Christian Camilo Castaño García

pp. $02-21$

Vol. 4 Núm. 1 | Enero-Junio de 2020

Pereira, Colombia 


\title{
DE LA UNIVERSIDAD REPUBLICANA A LA UNIVERSIDAD NACIONAL DE COLOMBIA: MODERNIDAD Y CONSTRUCCIÓN DE LA REPÚBLICA EN EL SIGLO XIX (1826-1867)*
}

FROM THE UNIVERSIDAD REPUBLICANA TO THE UNIVERSIDAD NACIONAL DE COLOMBIA: MODERNITY AND THE CONSTRUCTION OF THE REPUBLIC IN THE $1^{\text {TH }}$ CENTURY (1826-1867)

\author{
Christian Camilo Castaño García** \\ cccastanog@unal.edu.co
}

ORCID: http://orcid.org/0000-0003-1221-8130

$\begin{array}{cl}\text { Recibido: } & 29 \text { de enero de } 2019 . \\ \text { Revisado: } & 25 \text { de septiembre de } 2019 . \\ \text { Aceptado: } & 19 \text { de febrero de } 2020 . \\ \text { Publicado: } & 04 \text { de septiembre de } 2020 .\end{array}$

\section{Resumen}

En el presente trabajo se hace una revisión de fuentes primarias y secundarias sobre el recorrido histórico de la Universidad Republicana fundada en 1826 y su relación con la construcción de los proyectos republicanos del siglo XIX. Se pretende describir así la relación que existe entre el proceso de modernización del país y la educación superior, se resalta la incidencia del poder político y se comentan sus relaciones con la formación social y cultural de la época. Se defiende la tesis que considera que el tratamiento que se le da a la educación en el país y su relativo atraso en el siglo XIX se debe a una contradicción entre el proceso de modernización y el mantenimiento de las formas de sociedad y la mentalidad premodernas.

Palabras clave: Universidad Republicana, academia, liberalismo, reformas educativas.

\begin{abstract}
In the present work I review primary and secondary sources about the historical course of the Republican University founded in 1826 and its relation with the construction of the republican projects of the 19th century. The aim is to describe the relationship between the process of modernization of the country and higher education, highlighting the influence of political power and commenting on its relationship with the social and cultural formation of the time. The thesis I defend considers that the treatment given to education in the country and its relative backwardness in the nineteenth century, is due to a contradiction in the process of modernization with the maintenance of premodern forms of society and mentality.
\end{abstract}

Key Words: Republican University, academy, liberalism, educational reforms.

\footnotetext{
* Este documento respeta las directrices y normas dispuestas en la Declaración de Ética de Publicación de Ciencia Nueva, Revista de Historia y Política. Esta declaración puede consultarse en la página web de la revista: http://revistas.utp.edu.co/index.php/historia

** Politólogo de la Universidad Nacional de Colombia sede Bogotá. Profesor ocasional del Departamento de Ciencia Política de la Universidad Nacional de Colombia, sede Bogotá.
} 


\section{Las Reformas borbónicas y la ilustración}

Con la ascensión a la Corona española de la dinastía de los Borbones en 1713, después de varios años de guerra que culminaron con el Tratado de Utrecht y la paz de Rastatt, comenzaba la era de las reformas ilustradas en la península y en las colonias, conocidas como las reformas borbónicas. En este nuevo período, se pretendía reversar el camino trazado por la dinastía de los Austrias, que desde Carlos V se había propuesto salvaguardar la fe católica en Europa en tiempos de Lutero, imprimiendo en su mandato el sello de la contrarreforma. Los objetivos de las nuevas medidas fueron tres: 1) la centralización político-administrativa; 2) la modernización de la estructura socioeconómica y cultural del Imperio, y 3) la secularización política y social ${ }^{1}$. Todos tuvieron implicaciones en el ámbito de la educación, encarnados en la reforma de Moreno y Escandón a la Universidad. Dicha reforma confirmaba un proceso de cambios en buena parte del viejo continente, con algunos impactos en la España desde el siglo $\mathrm{XVI}^{2}$. Las necesidades de la Corona expresadas en las reformas de carácter administrativo y político, el embrionario ambiente ilustrado en España y sus colonias y la necesidad de adaptarse a una economía capitalista cada vez más robusta, que daba nacimiento a una nueva clase social (la burguesía), llevaba de manera inevitable a un cambio en la concepción de la educación; por ende, a una reforma educativa que creara un nuevo tipo de Universidad que supliera las necesidades de los nuevos tiempos. Se darían así las reformas del fiscal del virrey Guirior, Francisco Moreno y Escandón, que plantearían la creación de una Universidad pública bajo control estatal, en contravía con el monopolio eclesial de la educación y los claustros universitarios.

\subsection{La reforma de Moreno y Escandón}

Como se dijo anteriormente, los nuevos tiempos, los nuevos hombres y los nuevos desafíos demandaban una nueva y mejor educación por parte de la Corona. Tanto en el trono y la corte de Carlos III, como en los círculos intelectuales neogranadinos. Se señalaba la educación tradicional como causante de la terrible situación del reino y se propendía por una instrucción que fuera "útil", es decir, se proponía una educación más enfocada hacia las ciencias y la técnica en vez de la educación religiosa basada en la escolástica ${ }^{3}$. En esos años, a propósito de una polémica entre Mutis y los dominicos sobre una disertación en 1774 acerca del sistema copernicano - a lo cual Mutis decide sentar la queja a la Junta Superior de Aplicaciones-, el Virrey Guirior encomienda a Francisco Moreno y Escandón la elaboración de un plan de Estudios y la creación de una Universidad pública.

Dicho plan se proponía cambiar el método de enseñanza que hasta ahora predominaba, aquel basado en el magister dixit, el dictado y el memorismo. Además, pretendía abolir el juramento de fidelidad a la doctrina tomista y establecer la opción de elegir entre diversos autores católicos ${ }^{4}$. Todo esto precedido de una crítica vehemente al método tradicional denominado ergotista por el abuso de la silogística-, al considerar que este tipo de enseñanzas eran poco prácticas o útiles. El virrey Guirior y su fiscal pretendían cambiar así el programa de la Universidad colonial, la cual se componía de tres cursos: Artes, Teología

\footnotetext{
${ }^{1}$ G. A. Quesada, "Los movimientos sociales anteriores a la Independencia. Motines, protestas, rebeliones e insurrecciones en la América Española durante el siglo XVIII", en 1810: Antecedentes, desarrollo y consecuencias, M. Jaramillo (Bogotá D.C: Taurus, 2010), 97-150.

2 C. J. Reyes, "Los movimientos revolucionarios del siglo XVIII y su influencia libertaria", en 1810: Antecedentes, desarrollo y consecuencias, J. Mario (Bogotá D.C: Taurus, 2010), 53-93.

${ }^{3}$ F. González, Educación y Estado en la historia de Colombia. (Bogotá D.C: CINEP), 1970.

${ }^{4}$ González, Educación y Estado..., 21.
} 
y Cánones, cuyo contenido se tomaba de Aristóteles, Santo Tomás y los maestros escolásticos, y reemplazar el aprendizaje de esa "inútil jerigonza" por la enseñanza de ciencias prácticas, a tono con la época ${ }^{5}$.

El plan incluía el estudio de la matemática de Wolff (aritmética, álgebra, geometría, trigonometría); el estudio de Newton; el estudio de la geografía del virreinato, su flora, fauna y temas de agricultura. Todas estas materias necesarias para el desarrollo de una economía productiva que dejara de estar fundamentada en la extracción de minerales. Aun así, el plan de estudios conservaba algunos autores y textos de metafísica y ética que ya se estudiaban en la Universidad colonial, i.e., se continuaba con el estudio del derecho de la mano de Santo Tomás y sus comentadores (sobre todo de Melchor Cano). Lo novedoso en este último punto, era la introducción de teólogos franceses regalistas como Louis Abelly, Alejandro Natal, Claudio Fleury, Douviat, Antonio Agustín, Bernhard van Espen, etc. Todos ellos autores que no iban muy bien con la tradición de la autonomía y preponderancia del clero en la España heredada de los Austrias, muy latente en la colonia ${ }^{6}$.

Es por ese mismo motivo que se propone la creación de una Universidad pública totalmente financiada y controlada por la Corona. El propósito era debilitar la Universidad Tomista y su autonomía, para crear un claustro cuyo plan de estudios y metas académicas condujeran al fortalecimiento de una monarquía absoluta. Hasta el siglo XVIII, las únicas universidades en América que gozaban de financiación de la Real Hacienda y eran administradas por el Gobierno central de la Corona eran las universidades denominadas "oficiales", "mayores" o "generales", es decir, las universidades de México y Lima7. En el Nuevo Reino de Granada, como en la mayor parte de la América española, las universidades eran "menores" o "particulares", y eran fundadas por concejos o prelados y tenían funciones y cátedras restringidas. Según Diana Soto Arango:

En el Virreinato de la Nueva Granada se denominaba universidades a las instituciones que otorgaban grados académicos y formaban a los juristas y sacerdotes. En la capital, Santa Fe, localizamos cuatro instituciones de este carácter con la categoría de Universidades Menores, pero sólo dos otorgaban grados a seglares. La Universidad Javeriana los otorgó hasta 1767 y la de Santo Tomás hasta $1826^{8}$.

La propuesta del virreinato era convertir esas universidades menores en colegios, como el Colegio Mayor del Rosario o San Bartolomé. A la vez que se proponía fundar, con beneplácito del rey en real cédula del 18 de junio de 1778, la Universidad pública con reglamento similar a aquellas de México y Lima y con un plan de estudios determinado por el virreinato, cuyo fundamento era la reforma de Moreno y Escandón. Al respecto nos refiere Fernán González lo siguiente:

El Rosario dependía inicialmente de los arzobispos de Bogotá como patronos, pero la Corona asume el patronato al pasar al dominio de los clérigos diocesanos, pero continúa protegido por los arzobispos. El Rosario quedaría incorporado a la Universidad pública con S. Bartolomé. En S. Bartolomé se presentaron

\footnotetext{
5 J. Jaramillo, "Esquema histórico de la Universidad colombiana”, en La personalidad histórica de Colombia y otros ensayos, J. Uribe (Bogotá: Instituto colombiano de cultura, 1977), 238.

${ }^{6}$ González, Educación y Estado..., 20.

El regalismo era el conjunto de teorías o concepciones que defendían la supremacía del poder civil sobre el eclesiástico. En el caso de las monarquías absolutas, se trataba de defender las prerrogativas del poder monárquico, de regular asuntos de la vida pública por encima de las pretensiones de la iglesia.

${ }^{7}$ D. Soto, “Aproximación histórica a la universidad colombiana", Historia de la Educación Latinoamericana 7 (2005): 101-103.

${ }^{8}$ Soto, “Aproximación histórica a la universidad colombiana", 104.
} 
algunos conflictos de las autoridades civiles con los arzobispos, dado el carácter de Seminario y Colegio Real bajo el patronato [...] A veces se llegaba a una discordia escandalosa por lo cual el Arzobispo Virrey proponía la separación material de los edificios, aprovechando que tenían distintas rentas. Con eso mejoraría la calidad de la enseñanza pues eran muy distintas las ciencias necesarias para eclesiásticos que para abogados y burócratas. Bajo la dirección de los jesuitas, no había problema porque los jesuitas eran los patronos del colegio por la constitución del arzobispo. Con su expulsión, sus derechos pasaban al rey. Según Groot, se quería sustraer al Seminario de la jurisdicción eclesiástica9 .

Hasta 1767 las universidades coloniales gozaban de una plena autonomía, pues tenían sus propios planes de estudio, su propia organización administrativa y contaban con plena soberanía financiera. Los cambios que representaba la reforma de 1774 se correspondían al objetivo de fundar la Universidad pública para afectar la autonomía de las universidades en manos de la Iglesia. De esa manera se procuraba introducir el estudio de ciencias naturales, ciencias útiles que sirvieran al desarrollo tecnológico de España y sus colonias. Con la introducción de teólogos regalistas, también se procuraba avanzar en la consolidación de una monarquía fuerte, que tuviera suficiente control sobre el clero y los distintos ámbitos de la sociedad.

Sin embargo, estos objetivos se vieron truncados debido a que las reformas solo duraron cinco años y no pudieron desarrollarse a cabalidad, entre otras razones, porque la cantidad de catedráticos que se exigían (tres de Filosofía, cinco de Teología, cinco de Jurisprudencia) no se habían conseguido por falta de recursos y de maestros entrenados en las nuevas metodologías que se requerían, lo cual llevó a retomar el método escolástico de la dictatio y la disputatio. En la administración de Caballero y Góngora, se implementan algunas modificaciones, p.ej., dejando a voluntad de los estudiantes escoger entre la fílosofía práctica (matemáticas y física) y la especulativa (tradicional), y proponiendo un nuevo plan de estudios que conservaba buena parte de los programas de la Universidad colonial, añadiendo matemáticas, física newtoniana, geografía y botánica.

El proyecto de reformar la educación terminaría fracasando en 1789 cuando se negó la posibilidad de la fundación de la Universidad pública, y como consuelo se propuso tener una mayor intervención en las universidades eclesiales. De allí que los virreyes Ezpeleta y Mendinueta se quejaran de las condiciones de la educación de la colonia y propusieran de nuevo la creación de una universidad pública en Santafé ${ }^{10}$. De todas formas, a pesar del fracaso de la fundación de la Universidad pública, los frutos que rindieron las disputas de los virreyes y el ambiente ilustrado de la época dieron lugar a un cambio de mentalidad que resultaría en la gesta independentista. Los sucesivos planes de estudio y sus reformas, las tertulias santafereñas y el entusiasmo suscitado por Mutis y la expedición botánica, darían lugar a nuevas concepciones del mundo que iban más allá de la cerrazón católica y propendían por una enseñanza de carácter práctico y científico. Las reformas borbónicas que pretendían centralizar, modernizar y secularizar, todas evidentes en el objetivo trazado de fundar una universidad pública controlada por la Corona, una Universidad moderna que enseñara materias útiles y totalmente separada de los designios de las comunidades religiosas, si bien fueron inútiles, dejarían un precedente para la fundación de la Universidad Republicana, cuyo plan de estudios, diseñado por Santander, tendría como referencia las reformas de Moreno y Escandón.

\footnotetext{
${ }^{9}$ González, Educación y Estado..., 22.

${ }^{10}$ González, Educación y Estado..., 21.
} 


\section{La Universidad Central}

En la Independencia, después de 1810, se veía y sentía la urgencia de fundar la República una vez acabada la relación con España, para ello era necesaria una educación que pudiera dejar los lastres de la enseñanza colonial y por ende formar a los ciudadanos que la conformarían. Con esa preocupación, Francisco de Paula Santander se propone retomar la idea de una Universidad pública formulada por los virreyes borbones. Para ello se expide una ley que organizaría los distintos ámbitos de la educación en el país con el fin de fundar un nuevo sistema político, moderno y liberal. Por medio de la Ley del 18 de marzo de 1826, se intentaba cimentar una reglamentación minuciosa a la organización de la educación en su totalidad, pasando por los colegios nacionales o casas de educación pública, las universidades departamentales o también llamadas escuelas generales, hasta las universidades centrales en Bogotá, Quito y Caracas. Estas últimas tenían como objetivos el fortalecimiento de la naciente república, fomentar el estudio de las ciencias prácticas, difundir la ilustración y fomentar la creación y el arraigo de las instituciones liberales. Así se considera al comienzo de la Ley del 18 de marzo de 1826:

El Senado y la Cámara de Representantes de la República de Colombia, reunidos en Congreso, CONSIDERANDO: 1. Que el país en donde la instrucción está más esparcida, y más generalizada la educación de la numerosa clase destinada a cultivar las artes, la agricultura, y el comercio, es el que más florece por la industria, al mismo tiempo que la ilustración general en las ciencias y artes útiles es una fuente perenne y un manantial inagotable de riqueza y de poder para la nación que las cultiva: 2. Que sin un buen sistema de educación pública y enseñanza nacional no pueden difundirse la moral pública y todos los conocimiento útiles que hacen prosperar a los pueblos, DECRETAN... (Ley 18 de Marzo de $1826)^{11}$

En dicha legislación se incluía, tanto en colegios como universidades, la enseñanza de literatura, filosofía y ciencias naturales, jurisprudencia y teología (Ley 18 de marzo de 1826, artículo 33); adicionalmente, las universidades centrales ofrecerían unos cursos anexos con el motivo de abrazar "con más extensión la enseñanza de las ciencias y las artes" (artículo 42). Por ejemplo, en la clase de Filosofía y Ciencias Naturales, el estudio de astronomía y mecánica analítica y celeste, de botánica y agricultura, de zoología y de mineralogía, arte de minas y geognosia; en la clase de Literatura, historia literaria, antigua y moderna, y bibliografía (artículo 43). Adicionalmente, las universidades de Bogotá, Quito y Caracas ofrecerían la carrera de Medicina, que se componía de materias tales como: Anatomía General y Particular, Fisiología e Higiene, Patología General y de Anatomía Patológica, Terapéutica y Materia Médica, Clínica Médica, Cirugía y Clínica Quirúrgica, Farmacia y Farmacia Experimental, Medicina Legal y Pública (artículo 46). Así las cosas, las Universidades centrales quedaron divididas en cinco facultades: Filosofía, Jurisprudencia, Medicina, Teología y Ciencias naturales (artículo 46).

De igual forma, dicha ley reglamentó la vida universitaria hasta los mínimos detalles: los edificios, los requisitos de ingreso, los deberes de estudiantes y profesores, la expedición de títulos, entre otras cosas. Esto era un signo del esfuerzo del nuevo Gobierno por impulsar el desarrollo de un país en los términos del progreso enunciado desde la Revolución francesa y la modernización. Así mismo, el reglamento de la Universidad Central reflejaba algunos elementos del enfoque innovador - aunque autoritario - de la educación republicana: se prohibió la férula, se reservó la utilización de azotes solo para cuando los estudiantes

${ }^{11}$ M. Aguilera. Comp. Universidad Nacional de Colombia: génesis y reconstitución (Bogotá: Universidad Nacional de Colombia, 2001), 30-31. 
denotaran depravación, se debían hacer ejercicios militares, etc. ${ }^{12}$. Adicionalmente, la misión Zea permitió la contratación en 1822 de profesores extranjeros para que ayudaran con la modernización de las materias de estudio en el país. Entre ellos se encontraban el químico francés Jean Baptiste Boussingault, el botánico peruano Mariano Rivero, el naturalista Mario Goudot, el médico Désiré Roulin y el entomólogo James Bourdon (aunque la mayoría de ellos regresara un año después a Europa ${ }^{13}$. Con estas medidas se pretendía crear una clase ilustrada, liberal y científica que se encargaría de promover y fortalecer la República, secularizar la sociedad mediante la imposición de un sistema educativo de carácter oficial y consolidar un proyecto ilustrado.

Por todas estas razones, la fundación de una Universidad pública era una necesidad para la construcción de la nación, pero, además, era una clave importante para el desarrollo económico y político a la altura de las naciones europeas. Así lo expresa el secretario del Interior en su discurso de instalación de la Academia Colombiana el 25 de diciembre de 1826:

Esta corporación, creada en el presente año por la ley orgánica de estudios, se halla destinada a establecer, fomentar y propagar en Colombia el conocimiento y perfección de las artes, de las letras, de las ciencias naturales y exactas, de la moral y de la política [...] Así como principia la academia de Colombia, comenzaron las de Europa, que tan han contribuido a perfeccionar las artes, las ciencias y las bellas letras, y que son ahora el honor de las naciones a que corresponden [...] Si os detenéis últimamente en las ciencias políticas y morales, aún son de mayor importancia las materias que se ofrecen a vuestras meditaciones. Instituciones y leyes que reformar, para que hagan la felicidad de los pueblos; hábitos, usos y costumbres que mejorar, para que reine entre nosotros la virtud y se consoliden las instituciones liberales; ignorancia y preocupaciones que combatir; y, en fin, establecer, sostener y perfeccionar una educación general, que difunda las luces por todos los ángulos de Colombia; he aquí, señores, en compendio, lo que tenéis que hacer en las ciencias políticas y morales, que ejercen un tan poderoso influjo sobre la felicidad común ${ }^{14}$.

Para estos fines se decreta por parte del Ejecutivo el mismo año el plan de estudios, elaborado por José Manuel Restrepo, en el que se establecían los textos obligatorios para las distintas asignaturas en colegios y universidades.

\subsection{Universidad napoleónica: El plan de estudios de Santander y sus controversias}

El plan de estudios decretado por la presidencia en 1826 tenía por base algunos textos que marcaban claramente la inclinación liberal de la enseñanza, chocando fuertemente con los sectores tradicionalistas. A esto se correspondía una concepción napoleónica de la Universidad, concebida como una institución pública, laica y supervisada por el Estado. En últimas, se trataba de crear una corporación que siguiera los patrones de un proyecto de carácter republicano. La educación estaría inclinada a la formación profesional en vez de la investigación y gozaría de una autonomía relativa respecto al Estado ${ }^{15}$.

En esa dirección, se pretendía debilitar la influencia clerical en la educación y con la creación de la Universidad Central se llegó a suspender la Universidad Santo Tomás. En 1826 Santander decide trasladar la totalidad de los cursos que se daban en San Bartolomé y el Rosario a la nueva universidad, y suspendió la academia de $\operatorname{los}$ dominicos ${ }^{16}$. Con esto no se

\footnotetext{
${ }^{12}$ González, Educación y Estado..., 30.

13 Jaramillo, "Esquema histórico de la Universidad colombiana", 250.

${ }^{14}$ Aguilera, Universidad Nacional de Colombia..., 30-31.

15 J. M. Cobo, La enseñanza superior en el mundo: Estudio comparado e hipótesis (España: Narcea, 1979).

${ }^{16}$ Bushnell, D. El régimen de Santander en la Gran Colombia (Bogotá D.C: Tercer Mundo), 1966.
} 
pretendía acabar del todo con la incidencia de la clerecía, pues se continuó con el estudio de teología en la Universidad Central y el primer rector de esta fue el arzobispo Fernando Caicedo. De lo que se trataba era de asumir la educación del clero como un asunto del currículo de la Universidad laica, pues en los decretos expedidos para dar funcionamiento a la reforma se establecía que los colegios provinciales no ofrecieran más las clases de teología, reservándolas a la universidad, y admitiendo en algunos casos que colegios-seminarios se encargaran solamente de la formación del clero a la vez que debían ceñirse a las disposiciones del Gobierno central. Con dichas medidas se quería separar la formación de curas y seglares ${ }^{17}$. De todas formas, el plan de estudios no estuvo exento de controversias por la inclusión de textos obligatorios que eran considerados heréticos.

En los capítulos XXIII al XXVII del plan de estudios de 1826, en virtud de la mencionada Ley del 18 de marzo que funda las universidades centrales, se determinan los textos de enseñanza para las clases de literatura y bellas artes, filosofía y ciencias naturales, medicina, jurisprudencia y teología, respectivamente. En filosofía se utilizarían los textos de Desttut de Tracy y Condillac, y la matemática moderna de Lagrange y Bossuet; para la cátedra de jurisprudencia los tratados de derecho civil y penal de Jeremy Bentham, y en la enseñanza de teoría constitucional, se utilizarían las obras de Montesquieu, Tracy y Fritot. Entre estos autores, los más controversiales serían los materialistas Tracy y Bentham, así como algunos autores que se estipulaba fueran estudiados en la cátedra de derecho canónico, la mayoría de los cuales, según el conservador José Manuel Groot en su Historia eclesiástica y civil de la Nueva Granada "eran prohibidos por la Iglesia"18. Así se daba inicio a la muy conocida y prolongada "querella" benthamista, que enfrentó dos modelos de Universidad y de República.

Desde la introducción de los textos del filósofo inglés y del economista Jean Baptiste Say crecería una polémica con diversos miembros del clero y, en general, dentro de la intelectualidad colombiana. Ya el presbítero Francisco Margallo criticaba la introducción de las obras de Bentham desde el púlpito, dirigiéndose contra Vicente Azuero, hombre de Santander y quien daba clases de jurisprudencia en la naciente Universidad Central. En una representación enviada al Poder Ejecutivo, Vicente Azuero afirma, en respuesta a Margallo, lo siguiente:

El ministerio de la predicación entre nosotros es una función pública que no puede ejercerse sino con consentimiento o aquiescencia del gobierno, y sin pasar los límites fijados en las leyes. Nadie puede convocar al pueblo en un lugar público, arengarlo y proclamarlo sin permiso de las autoridades constituidas. Cuanto más sagrado sea el lugar donde se tiene la reunión, cuanto más santo sea el objeto, o el pretexto con que se le congregue, tanto más derecho tiene el gobierno a usar de su suprema e imprescriptible inspección para cuidar de que no se perturbe el orden público, y de que no se abuse de estas santas funciones. El oficio del predicador tiene sus restricciones y su responsabilidad, lo mismo que cualquiera otra ocupación pública. Su misión es explicar sencillamente el dogma y recomendar las buenas costumbres. Cuanto exceda de estos dos exclusivos objetos es un abuso, una usurpación digna de castigo ${ }^{19}$.

\footnotetext{
${ }^{17}$ J. Lane, La reforma universitaria de la Nueva Granada: 1820-1850 (Bogotá D.C: Instituto Caro y Cuervo, 1994), 42.

${ }^{18}$ Aguilera, Universidad Nacional de Colombia..., 98.

${ }^{19}$ L. H. López, Obra educativa: La querella benthamista 1748-1832 (Bogotá D.C: Fundación Francisco de Paula Santander, 1993), 28.
} 
Ante esto el Ejecutivo, en su respuesta a Azuero, tramita su querella con las autoridades correspondientes para hacer un llamado al presbítero por criticar la ley ${ }^{20}$. El mismo año, Antonio Alvarado, en defensa de Margallo y su oposición a la enseñanza de Bentham en la universidad, escribió en 1826 cuatro cartas intituladas "Cartas críticas de un patriota retirado a un amigo residente de la ciudad en que se descubre y manifiesta el verdadero fanatismo". En la última, se resumen las objeciones más comunes de los detractores del plan de estudios, la cuales llama "errores de la obra de Jeremías Bentham". Entre estas, afirma que en la propuesta del filósofo inglés se reniega de la ley natural y se la tilda de fantasía; la afirmación de la inexistencia de la conciencia; que el derecho de la Iglesia debe ser reglado por el príncipe y que el orden civil debe basarse en la tolerancia; concibe la religión como una convención útil para el dominio político; que la Iglesia debió permitir la discusión de las herejías del Lutero; considera como delito o reprobable el ayuno, la continencia, etc. ${ }^{21}$. Este tipo de quejas fueron recurrentes, siendo muy famoso el libelo anónimo "El cuchillo de San Bartolomé" y la representación realizada al Congreso de la República por el arzobispado, cleros y padres de familia solicitando la proscripción de la enseñanza del Tratado de Legislación de Bentham ${ }^{22}$.

En todo este asunto estaban en disputa dos modelos de Universidad: la Universidad napoleónica-republicana y la universidad tradicional. De la misma manera, estaban en confrontación dos modelos de república, que serían los sucesivos proyectos de los partidos Liberal y Conservador. Se trataba de una contienda entre la concepción de un estado reformista y un estado reaccionario, reacio a los elementos más intrínsecamente modernos. En el modelo reformista, se valoraba un tipo de educación científica y técnica, con una perspectiva de la educación como innovación y discusión racional de los asuntos públicos. En el modelo universitario reaccionario, se valoraba más una pedagogía de corte tradicional humanista que concebía la educación como una actividad de transmisión de las tradiciones basado en el método escolástico, método en el que la autoridad es decisiva, el magíster dixit ${ }^{23}$. Esto llevaría a algunas modificaciones en las reformas planteadas inicialmente y, más tarde, al fracaso del proyecto de la Universidad reformista. Así mismo, se puede ver que el punto en discusión respecto a las ideas de Bentham tenía que ver con su materialismo, inaceptable para una concepción de la vida y de la sociedad basada en el desprecio del cuerpo, considerado como fuente de toda depravación, oponiéndole los principios espiritualistas propios del catolicismo, de los cuales puede derivarse dogmáticamente una serie de prescripciones sobre el comportamiento moral de los individuos en su vida pública y privada, llegando incluso a establecer las actitudes políticas propicias para una república. Todo esto estaba enmarcado en las teorías milenaristas y conspirativas acerca de la masonería que difundía la iglesia en la parroquia y sus sistemas educativos.

Aun así, debemos recordar que, a pesar de los esfuerzos por fundar la Universidad estatal y cimentada en los valores ilustrados, en el artículo 229 del plan se incluye una advertencia que deja ver las tendencias autoritarias del Ejecutivo y la intervención del Estado en la conducción moral de la nación con una mira al mejoramiento del ciudadano, pero a la vez del mantenimiento del orden tradicional, afirmando que:

\footnotetext{
${ }^{20}$ Domínguez, Obra educativa ...,50-51.

${ }^{21}$ Domínguez, Obra educativa...,77-78.

${ }^{22}$ Domínguez, Obra educativa..., 95-101.

${ }^{23}$ J. Ocampo, “", Revista de Historia de la Educación Colombiana 3 y 4 (2011): 39.
} 
Los autores designados en este decreto para la enseñanza pública no se deben adoptar ciegamente por los profesores en todas sus partes. Si alguno o algunos tuvieren doctrinas contrarias a la religión, a la moral y a la tranquilidad pública, o erróneas por algún motivo, los catedráticos deben omitir la enseñanza de tales doctrinas, suprimiendo los capítulos que las contengan y manifestando a sus alumnos los errores del autor y autores en aquellos puntos, para que se precavan de ellos, y de ningún modo perjudiquen a los sanos principios en que los jóvenes deben ser imbuidos ${ }^{24}$.

De igual manera, debemos decir que las reformas que intentaban debilitar la función del clero en la educación y delimitar de manera decisiva los ámbitos de la enseñanza para curas, y, por otra parte, aquella propicia para laicos, fueron infructuosas dadas las resistencias de sectores amplios de la sociedad y las limitaciones económicas y burocráticas del naciente Estado. A pesar de la prohibición, varios colegios departamentales siguieron enseñando derecho público y eclesiástico, así como se mantuvo la enseñanza de teología en ámbitos compartidos por seminaristas y laicos ${ }^{25}$. Más tarde, mediante Decreto del 12 de marzo de 1828, Bolívar, en la época acuñada por Santander como "la dictadura", prohibió los textos de enseñanza de Bentham, lo cual sería ratificado después de la conspiración septembrina, pues se acusaba de participar en ella a estudiantes universitarios influenciados por las ideas del filósofo utilitarista.

Con todo, las reformas realizadas por el gobierno de Santander en materia educativa fueron insuficientes, principalmente en lo que concierne a la educación universitaria. La misión Zea no rindió ningún producto, pues casi todos los académicos que llegaron al país para fortalecer la enseñanza de las ciencias volvieron a sus lugares de origen, sin hacer mayor aporte a la academia colombiana. Los deficientes recursos fiscales no permitieron financiar los requerimientos más importantes para la enseñanza superior. No se contemplaba una buena paga a los profesores, incluso recomendando que aquellos que recibieran rentas de algún otro tipo ofrecieran su labor docente de manera gratuita ${ }^{26}$. El número de universidades planteado desde el principio era insuficiente para satisfacer la demanda de un territorio tan extenso compuesto por Colombia, Venezuela, Panamá y Ecuador, lo que llevó a Santander a elevar en 1827 los colegios de Popayán y Cartagena al rango de universidades ${ }^{27}$, lo que a su vez impidió garantizar el monopolio de la educación por el Estado, que no pudo reservar el derecho de ofrecer un currículo profesional solo a las universidades oficiales, pues en los colegios departamentales se continuó enseñando Derecho Público y Eclesiástico, así como Teología y algunas otras materias. Igualmente se tuvo que modificar el programa para obtener los títulos de doctor, requeridos para ejercer el derecho o la medicina. En 1826 se estipulaba que eran necesarios tres años en el colegio, seguidos por tres en el bachillerato y tres años más para obtener un doctorado; en 1835 se reducía todo el procedimiento de seis a cinco años, eliminando un año para obtener el título de doctor y permitiendo que los estudiantes vieran tantos cursos como quisieran. Al respecto, Lane afirma:

Lo que resulta imposible defender es la política que permitió que los estudiantes tomaran tantos cursos como quisieran. Santander aparentemente la firmó con el propósito de que el estudiante dotado o aventajado no detuviera su progreso en aras de los menos dotados y más lentos. Pero después de cinco años de ensayo, se pudo demostrar la verdadera importancia de esta medida. En 1840, el vicerrector de la Universidad de Bogotá declaró que cualquier reforma sería infructuosa si esta ley continuaba permitiendo que los estudiantes registrarán tantos cursos como podían. Y, en efecto sucedió que los

\footnotetext{
${ }^{24}$ Aguilera, Universidad Nacional de Colombia..., 100.

${ }^{25}$ Lane, J. La reforma universitaria..., 43.

${ }^{26}$ Aguilera, Universidad Nacional de Colombia..., 117.

${ }^{27}$ Lane, J. La reforma universitaria..., 45.
} 
estudiantes que no tenían más tiempo que el necesario para ir de un salón a otro obtenían calificaciones que representaban nada más que su asistencia a las conferencias ${ }^{28}$.

De todas formas, como lo denunciaran José Manuel Groot, Ángel y Rufino J. Cuervo, el resultado de la fundación de la Universidad Central fue espurio, pues de allí no salió un solo químico, un solo físico, un solo naturalista de renombre y con inclinaciones investigativas a causa del estado miserable de los laboratorios y del precario presupuesto para los profesores y catedráticos, predominando los abogados y teólogos que se ocuparían de la demagogia y se lucrarían del poder político en desmedro del avance tecnológico necesario para la explotación de recursos y materias primas en el país ${ }^{29}$.

El proyecto de la Universidad como eje fundamental de una república moderna fracasó en su germen por todo lo que ya anotamos. Además por las graves convulsiones políticas de la época, que no solo afectaron a la Universidad sino que tuvieron en ella un escenario predilecto respecto de las disputas ideológicas, impidiendo, por ejemplo, que después de la derrota de los santanderistas en las elecciones, se designara como rector a Florentino Gonzáles, que por ser del partido de Santander y un liberal convencido en materia política y económica, no recibiría el aval del presidente José Ignacio Márquez, quien propendía por una universidad de carácter tradicional. Al respecto, cabe citar una anécdota que anota el ilustre historiador colombiano Jaime Jaramillo Uribe cuando en 1836 el Doctor José Rufino Cuervo fue elegido rector de la Universidad Central:

El presidente le comunicaba su elección en los siguientes términos: 'Los doctores de esta Universidad han anulado la sentencia pronunciada contra usted por Broussais en segunda instancia; ellos le han nombrado rector en concurrencia con el doctor Soto, y el Gobierno ha aprobado la elección prometiéndose que usted acepte el rectorado por amor a la educación, por gratitud a los electores y por interés en favor de este establecimiento literario que debiendo ser el primero de la República, es el último ${ }^{30}$.

\section{Los distritos universitarios en las presidencias de Pedro Alcántara Herrán y Tomás Cipriano de Mosquera}

Más adelante, después de la guerra civil en 1840, comienza una reforma al sistema educativo en Colombia por la mano de Mariano Ospina Rodríguez y bajo la presidencia de Pedro Alcántara Herrán, con un fuerte componente modernizador, aunque con un explícito contenido autoritario. El plan de estudios expedido en 1842 lo demuestra, el cual tenía tres metas cardinales:

... la primera, sujetar los alumnos a severa disciplina, así en sus costumbre y moralidad como en sus estudios y adquisición de grados profesionales; la segunda, introducir el elemento religioso en la dirección universitaria, completando la instrucción con la educación; y la tercera, reorganizar las enseñanzas de manera que en ella se introdujeran elementos conservadores (como el estudio del derecho romano, por ejemplo) y algunos de literatura y humanidades que habían sido muy descuidados, y que al mismo tiempo se proscribiesen ciertas materias calificadas de peligrosas por el gobierno, tales como la ciencia de la legislación, ciencia constitucional y táctica de las asambleas ${ }^{31}$.

\footnotetext{
${ }^{28}$ Lane, J. La reforma universitaria..., 50.

29 Jaramillo, "Esquema histórico de la Universidad colombiana", 251.

30 Jaramillo, "Esquema histórico de la Universidad colombiana", 251.

${ }^{31}$ Jaramillo, "Esquema histórico de la Universidad colombiana", 252.
} 
Dicho plan de estudios había sido creado para todo el sistema educativo, desde las escuelas hasta las universidades, y constituía una afrenta al sistema que imperaba hasta el momento, que basaba su pedagogía en la repetición y la memorización ${ }^{32}$. Esta reforma y la gestión de Mariano Ospina Rodríguez propugnaron por un cambio en la pedagogía para que esta tuviera una característica más explicativa y no memorística o ergotista, como aquella que se enseñaba en la colonia. La innovación del nuevo plan de estudios dio un lugar importante a la Universidad, la cual estaba en decadencia, dividiendo la República en tres distritos universitarios: Bogotá, Cartagena y Popayán, teniendo todas sus directrices en la Universidad de Bogotá que sería el antecedente directo del proyecto de la Universidad Nacional.

El primer objetivo de la reforma, aquel de disciplinar a los estudiantes, tuvo mucho éxito a causa del efectivo control que hubo por parte de las autoridades nacionales de la conducta de los estudiantes de colegios y universidades ${ }^{33}$. Pronto, las universidades lograron mejorar el nivel de la discusión y se dio paso a la creatividad de los educandos. Ya no se trataba tanto de memorizar las lecciones de gramática y literatura, sino que ahora se trataba de componer, escribir e incluso dibujar. Los tiempos libres se destinaban para la lectura, y ya se abrían espacios para la difusión de la creación literaria en periódicos como El Eco de la Universidad o El observador fundado por Miguel Samper.

La ciencia y la medicina ocuparon la atención del gobierno en 1842. Al terminar este año se organizó la enseñanza de la práctica médica en el Hospital de San Juan de Dios, mediante un convenio con la Universidad de Bogotá. Para las clases de ciencias naturales, física y matemáticas fueron nombrados dos profesores locales y dos más fueron solicitados a Europa. Los instrumentos necesarios para estas cátedras, así como también otros elementos para las demás asignaturas y libros para la Biblioteca Nacional, fueron también requeridos a Europa. Como resultado de estas gestiones, en 1846 la Universidad de Bogotá recibió una buena biblioteca médica y excelentes instrumentos quirúrgicos ${ }^{34}$.

Estos avances se sumaban a las cátedras que se dictaban en el Rosario, que era parte de la Universidad, donde llegaban los avances de la educación europea, como las cátedras de literatura inglesa, dibujo y música para estudiantes de filosofía y literatura.

Por su parte, Tomás Cipriano de Mosquera permitiría dar lugar a nuevos avances en la educación en general, y en especial, a la educación universitaria. Con Rufino Cuervo en la vicepresidencia se redacta un nuevo Plan de estudios en el que se incluían nuevas cátedras para ser enseñadas en las universidades. Las cátedras de Derecho y Medicina, por recomendación del presidente, ahora debían ser restringidas en algunos claustros y no estar más dispersas por los distintos colegios y universidades del país. Además, se incluirían cátedras como Usos del Vapor en la Fuerza Motriz, Aplicación del Vapor a las Máquinas, Construcción y Administración de Ferrovías, Botánica de la Zona Tórrida, Agricultura Subtropical e Higiene para los Trabajadores de las Minas ${ }^{35}$.

Para la misma época se patrocinó la creación de una academia de dibujo y pintura en 1847, se hizo la apertura del Colegio Militar de Bogotá y se impulsó la Escuela Práctica de Arquitectura. El balance de la educación era positivo, especialmente en cuanto a la educación

32 "El Desarrollo de la Educación en Colombia", E. Ahern, acceso el 27 de enero de 2014, http://www.pedagogica.edu.co/storage/rce/articulos/rce22-23_04arti.pdf

33 "El Desarrollo de la Educación en Colombia", E. Ahern, 48.

34 "El Desarrollo de la Educación en Colombia", E. Ahern, 49.

35 "El Desarrollo de la Educación en Colombia", E. Ahern, 50. 
superior. Sin embargo, las reformas adelantadas por los Gobiernos de Herrán y Tomás Cipriano de Mosquera tenían un carácter paradójico, pues a pesar de algunos elementos modernizantes respecto a las nuevas cátedras dictadas en las universidades, se había restituido un control directo de la Iglesia sobre el contenido de las enseñanzas en Derecho y Filosofía, prolongando muchos años más la controversia Benthamista. Jaime Jaramillo Uribe, citando a José María Samper, deja ver las ventajas y las desventajas de las reformas adelantadas por los dos gobiernos en materia de educación, sobre todo respecto a la reforma de Mariano Ospina Rodríguez. Samper decía que si bien el primer objetivo había tenido un buen resultado por la disciplina de estudio que adquirieron los estudiantes, los otros dos habían sido más bien contraproducentes:

En cuanto al segundo propósito [...] las cosas fueron demasiado lejos. Clérigos eran el rector, el inspector, jesuitas los profesores de San Bartolomé, sin contar todos los empleados y catedráticos de la facultad de Teología, y el rigor que había en las prácticas religiosas suscitaba en la mayor parte de los alumnos una reacción en sentido contrario. También fue contraproducente el tercer objetivo. Los estudiantes buscaban por su propia cuenta el contacto con las ciencias políticas de su tiempo y los libreros se los ofrecían abundantemente ${ }^{36}$.

\section{La Universidad en el romanticismo liberal y el radicalismo liberal de mediados del siglo XIX}

Pero el ambiente no mejoró en los Gobiernos que sucedieron a los de Herrán y Tomás Cipriano de Mosquera, la época conocida como el romanticismo liberal, caracterizada por una fuerte inspiración ideológica en el pensamiento liberal de tinte utópico. En el Gobierno liberal de José Hilario López se querían llevar hasta las últimas consecuencias las libertades individuales, en las que se incluían la libertad de enseñanza y ejercicio profesional. Por ley de 15 de mayo de 1850 se eliminaba la exigencia de título académico para el ejercicio del Derecho, la Medicina, la Ingeniería y el Sacerdocio con excepción de la Farmacia, y se suprimen las universidades para convertirlas en colegios nacionales.

El argumento de los románticos era que la educación superior era un refugio de los rezagos coloniales, pues el título universitario se había convertido en un sustituto de los títulos de nobleza. En ese sentido, los románticos mandaron al traste la educación superior, prefiriendo auspiciar la educación básica para los campesinos y la mayoría de la población colombiana. Después de una época convulsiva en la que se dieron tres guerras civiles y un golpe de Estado donde las instituciones tradicionales fueron fuertemente cuestionadas, el país siente la necesidad de fomentar la educación, esta vez bajo un modelo universitario fuerte, además, de carácter laico y promovido en el auge del radicalismo liberal. En 1864 José María Samper presentaría un proyecto de ley que sería la base para la ley orgánica de la Universidad, y el 26 de septiembre de 1867 se sanciona en el Congreso la Ley 66 "con el objeto de organizar una Universidad Pública de la Capital de la República, la que llevará el nombre de Universidad Nacional de los Estados Unidos de Colombia" ${ }^{37}$.

\footnotetext{
${ }^{36}$ Jaramillo, "Esquema histórico de la Universidad colombiana", 253.

37 "Reseña histórica de la Universidad Nacional de Colombia Sede Medellín", Universidad Nacional de Medellín, acceso el 10 de junio de 2020, https://docplayer.es/5773073-Resena-historica-de-la-universidadnacional-de-colombia-sede-medellin-oficina-de-planeacion.html
} 


\section{Fundación de la Universidad Nacional de Colombia}

La fundación de esta Universidad tenía como trasfondo un claro objetivo político que se enmarcaba en las ideas del radicalismo liberal:

Libertades absolutas, federalismo, separación de las dos potestades, fe en la razón y en el progreso, papel supletorio del Estado en el proceso económico. En efecto, El Olimpo Radical fue moderno precisamente porque reabrió y fundó la universidad para la Nación, lugar de enseñanza de la ciencia ${ }^{38}$.

Paralelamente, el país se recuperaba económicamente y entraba a hacer parte en la economía mundial, gracias a la exportación del tabaco, que generaba divisas importantes. Se comenzaba a pensar en una industrialización y en la construcción de nación en un país fragmentado por los cacicazgos regionales y las desde ya pronunciadas diferencias territoriales en sus identificaciones partidistas:

La Universidad se inició con seis escuelas o facultades: las clásicas facultades de Jurisprudencia, Medicina y Filosofía y Letras, y la Escuela de Ciencias Naturales, la de Ingeniería y el Instituto de Artes y Oficios. También conformarían el plantel una serie de instituciones capitalinas como: la Biblioteca Pública, el Museo de Ciencias Naturales, el Laboratorio de Química de la Facultad de Medicina y los hospitales. Se elimina el Colegio Militar (reabierto en 1866) y la Escuela Politécnica creada por Mosquera en 1861. Los recursos y el personal de estas instituciones ingresaban a la Universidad, que sería financiada por la Nación, el Estado de Cundinamarca y el Municipio de Bogotá39.

En 1868 se expidió el estatuto orgánico de la institución, y en febrero del mismo año abriría sus puertas con 335 estudiantes y 45 profesores, teniendo por primer rector a Manuel Ancízar. Sin embargo, la Universidad de nuevo sufría los problemas de financiación, pues los gastos premeditados para su mantenimiento se elevaron más allá de lo esperado, teniendo que financiarse en un $19 \%$ con rentas propias. Las clases de las distintas facultades tendrían como sedes, en los distintos lugares de Bogotá, el Colegio San Bartolomé, la Candelaria, Santa Inés, el Carmen, San Juan de Dios y El Colegio Militar, y como catedráticos figuraban personalidades intelectuales de ambos partidos, Liberal y Conservador, tales como el mismo Manuel Ancízar, José María Samper, Liborio Zerda y Miguel Antonio Caro, entre otros ${ }^{40}$. Los estudios solían durar seis años debido a que la Universidad también se encargaba de la enseñanza media, equivalente al bachillerato contemporáneo. Había materias que eran obligatorias para todos los alumnos: un curso de biología, uno de sociología y dos de historia. Los alumnos no podían tomar más de tres cursos al año y solo al final se les permitía ver cuatro asignaturas a la vez.

En los comienzos de la Universidad, se contaba solamente con tres profesores titulares y 43 catedráticos:

... que tenían que ganarse la vida mediante la acumulación de varios cargos y desempeñando las más variadas ocupaciones, eran funcionarios, jueces, diputados, políticos, ingenieros, periodistas, escritores, médicos atareadísimos y dedicaban algunos de sus ocios a dar clases en la Universidad que era una

\footnotetext{
${ }^{38}$ L. A. Zambrano, "Universidad, sujeto y radicalismo liberal colombiano: El régimen de gobierno de la moral de los sujetos", Educere. Investigación arbitrada 14, n. 49 (2010): 323.

39 "Reseña histórica de la Universidad Nacional de Colombia Sede Medellín", Universidad Nacional de Medellín, 15.

${ }^{40}$ Zambrano, "Universidad, sujeto y radicalismo liberal colombiano: El régimen de gobierno de la moral de los sujetos", 384.
} 
distinción muy solicitada [...] la retribución de los profesores era tal que, en la mayoría de los casos había que darse por satisfecho con que acudieran a dar sus lecciones ${ }^{41}$.

Esto constituía una continuidad respecto del primer intento de Universidad estatal en Colombia, la Universidad Central, donde se prohibía contratar profesores que no tuviesen ya otra fuente de ingresos, pues la docencia desde el principio constituyó más un acto de fe que una profesión bien retribuida.

También hubo una persistencia en lo referente a la rigurosa reglamentación del comportamiento de los alumnos, así como el establecimiento de sanciones por mala conducta dentro y fuera de los claustros. Según los estatutos de la Universidad, existía una serie de actores encargados de la vigilancia del comportamiento de los estudiantes de las distintas facultades y se fabricaron distintos formatos que permitían calificar la conducta de los educandos en las diferentes clases. Dentro de los agentes que se encargaban del orden estaba el rector, quien dentro de sus funciones debía ocuparse de

... la suprema vigilancia de los catedráticos en cuanto a la asistencia y puntualidad de las clases, cuidar la asistencia de los cursantes a las clases y a todos los actos, corregir a los que falten y mantener el buen orden y la disciplina a dichos actos ${ }^{42}$.

Los profesores, tanto los principales como los sustitutos debían llevar un registro de los alumnos todos los días y en todas las clases, el cual debían entregar al director de la Escuela todos los sábados. Esto servía para sugerir quienes, en su concepto, debían ocuparse en otros oficios y abandonar la academia. Así mismo estaban las figuras del vicerrector en las Escuelas de Filosofía y Letras, Ingeniería y Militar, y el bedel de las clases, equivalente al monitor, pero con funciones de vigilancia ${ }^{43}$. En el ámbito académico de la Universidad se resucitó la polémica frente a los textos de Bentham y otros tantos con raigambre liberal. Si bien el claustro era habitado por personajes de todas las ideas y de ambos partidos, las discusiones acerca de los textos de enseñanza tuvieron que darse en virtud de la Ley 1867 que otorgaba un grado de autonomía administrativa bastante amplio, pero que, al igual que el plan de estudios de la universidad de Francisco de Paula Santander, establecía los textos obligatorios para la enseñanza en la cátedra, de nuevo introduciendo los textos de Jeremy Bentham y Destutt de Tracy. Gracias a la polémica renunció a la rectoría Manuel Ancízar quien optó por un "eclecticismo en materia de doctrinas filosóficas y políticas" tomando la vocería por la libertad de cátedra.

Luego de la cruenta guerra de los setenta, la Universidad empezaría a fluctuar bajo las necesidades políticas del país y al vaivén de los conflictos entre los partidos políticos, que cada vez eran más agudos. Vendría la Regeneración, ese momento histórico tan importante para toda reflexión acerca de la historia nacional, un momento donde el Estado se hizo más fuerte a causa de la decadencia económica del cultivo de tabaco, convirtiéndose en la salvación para todos aquellos doctores que vivirían de los dineros públicos y los contratos leoninos:

\footnotetext{
${ }^{41}$ Jaramillo, "Esquema histórico de la Universidad colombiana", 261.

${ }^{42}$ Zambrano, "Universidad, sujeto y radicalismo liberal colombiano: El régimen de gobierno de la moral de los sujetos", 387.

${ }^{43}$ Zambrano, "Universidad, sujeto y radicalismo liberal colombiano: El régimen de gobierno de la moral de los sujetos",387-388.
} 
Núñez y caro, las figuras centrales del movimiento de la Regeneración, estaban convencidos de que las orientaciones que el sistema educativo había tenido durante los gobiernos radicales eran una de las causas directas de la inestabilidad política y la desazón social que el país había vivido en las décadas anteriores. A esa convicción correspondió la reforma constitucional del 86 y la firma en 1887 de un nuevo concordato con la Santa Sede, que dieron a la Iglesia amplia intervención en la marcha de la educación pública. La Universidad regresó al control directo del Estado, perdiendo no sólo su limitada autonomía sino su unidad académica. Cada una de las Escuelas fue colocada bajo la dirección del ministerio correspondiente. En esa forma funcionaron sus diferentes facultades hasta que se produjo la reforma de $1935^{44}$.

\section{Modernización sin modernidad}

Luego del recorrido histórico que se hizo por la historia de la Universidad Republicana hasta la fundación de la Universidad Nacional de Colombia, es necesario hacer un breve análisis acerca de la importancia que tuvo esta institución en la formación de una república moderna y secular, identificando los aciertos y falencias del proyecto moderno que la tuvo por fundamento.

Desde la colonia y con las reformas borbónicas, se planteó el reto de una educación que atendiera los retos de la modernización, entendida en su aspecto tecnológico y económico. La meta era una cuestión de racionalidad instrumental, se trataba de fomentar una educación que estuviera al servicio del Estado, formando una capa intelectual que pudiera convertirse en su leal burocracia y animando el estudio de ciencias útiles para el fortalecimiento de una economía basada en una producción eficiente y diversificada que ya no dependiera tan solo de la extracción de metales ${ }^{45}$. El afán del plan de estudios de Moreno y Escandón se centraba en la introducción de las ciencias naturales y el control estatal de la formación en Jurisprudencia y Teología, todas estas materias apoyadas en autores regalistas. Además, cabe afirmar que la ilustración española estuvo mucho menos influenciada por los avances filosóficos hechos en Francia y Alemania en lo respectivo a cuestiones sociales y políticas que lo que realmente estuvo en cuestiones científicas. En este sentido, los primeros ilustrados españoles fueron lo que se ha denominado como 'novatores', i.e., pensadores que rehuían del legado escolástico y sus soluciones teológicas-metafísicas, optando por abrazar más las ciencias naturales y su método inductivo. Esta generación prefería escribir en castellano, aborreciendo el latín, y estaban mucho más interesados en la divulgación científica que en cuestiones de filosofía, teología y/o jurisprudencia ${ }^{46}$. Las quejas de criollos y españoles respecto de la educación ergotista hallaban en estos pensadores sus antecedentes y por ello demandaban ante todo la enseñanza de materias prácticas y útiles, deseaban aprender sobre todo cuestiones de filosofía natural.

De otra parte, por su raigambre social y el estado de las formaciones sociales americanas, estos hombres que pretendían recogerse en la era de las luces, también eran los herederos y beneficiarios de la sociedad colonial de los privilegios. La falta de una economía lo suficientemente avanzada en España y la derrota en 1521 de los comuneros de Villalar, habían sepultado desde tiempos de los Austria la posibilidad de la emergencia de la burguesía, en cuyo seno surgirían las reivindicaciones igualitarias y liberales del tercer

\footnotetext{
${ }^{44}$ Jaramillo, "Esquema histórico de la Universidad colombiana", 262.

${ }^{45}$ Es importante recordar cómo desde las reformas borbónicas, uno de los más grandes obstáculos era el monopolio comercial de Cádiz y la gran afrenta que para la Corona representaba las mercaderías inglesas y su expansión.

${ }^{46}$ R. Antolínez, "La filosofía del siglo XVIII. Novatores e ilustrados", en La filosofía en América Latina, G. Marquínez (Bogotá D.C: El Búho, 1993), 115-119.
} 
estado. Los nuevos hombres no eran tan nuevos, y esto tendría sus implicaciones en el proyecto independentista y republicano, por ende, también en las sucesivas reformas al sistema educativo y los planes de estudio. En este respecto vale recordar el miedo que tenía Bolívar de la ascensión social de negros e indígenas en la 'democracia' y su inclusión en la vida pública, a lo cual denominó la "pardocracia"; o incluso su personalidad de aristócrata ${ }^{47}$.

Por todo esto el proyecto de Universidad desde finales de la Colonia y a lo largo del siglo XIX, si bien estaría imbuido de las nuevas corrientes de pensamiento, tan solo lo sería en su proyecto de modernización de la estructura económica, la enseñanza de las ciencias y en algunas reformas políticas de carácter administrativo. En contraste, todos aquellos elementos que podrían ser considerados modernos en términos de la sociedad y mentalidad de los individuos que la componen (la eliminación real de los privilegios, la práctica de la tolerancia y la secularización de la esfera pública y del Estado), se verían más bien truncados y camuflados por los diferentes intentos de reforma, "una modernización sin modernidad"48.

Este conflicto en la experiencia de la modernidad colombiana se hace evidente en las disputas académicas y políticas respecto de los sucesivos planes de estudio. Las controversias que surgieron y se mantuvieron en la Universidad colombiana desde tiempos de Moreno y Escandón son una muestra de la inexistencia de la tolerancia en nuestra cultura. Esto como producto de la pesada herencia de las políticas de la contrarreforma europea, la cual instauró en España y sus colonias una mentalidad de desprecio a todo lo extraño, lo diferente y a la diversidad de opiniones, lo que influenciaría de manera determinante los procesos de ilustración ${ }^{49}$. Vale recordar que, entre las polémicas suscitadas por el plan de estudios de 1826, se encontraba no solo la inclusión de los textos de Bentham y Tracy, sino también la enseñanza del derecho internacional de Emmer de Vattel por la simple razón de ser de origen protestante. Los esfuerzos por no permitir que dentro del plan de estudios se incluyeran este tipo de lecturas eran deudores de las censuras a la literatura herética del XVI en España, lo cual hacía parte del adoctrinamiento que ejercía la Iglesia en los centros educativos bajo su control, desde la catequesis y la prédica en las parroquias.

Dentro de dichos procesos de socialización que formarían a revolucionarios y reaccionarios del nuevo siglo, debe tenerse en cuenta la enseñanza eclesial, que era la expresión y confirmación de una formación social premoderna, que sentaba sus bases en lo que Fernando Guillén Martínez denominó la "estructura de asociación de la hacienda", esta a su vez heredera de la encomienda, en la cual se formó la personalidad autoritaria del colombiano, un tipo de mentalidad que tiene sus expectativas de ascensión social en la cercanía y obediencia a sus autoridades inmediatas ${ }^{50}$. El método del magíster dixit, y el argumento $a b$ auctoritate, propio de la enseñanza escolástica, tenía su fundamento en una sociedad de carácter vertical fundada en los privilegios heredados, en últimas, de una estructura de asociación fundada en los títulos de nobleza o de hidalguía y en la adherencia militante a las causas de los señores de la tierra. Al respecto, Rafael Gutiérrez Girardot señala

\footnotetext{
${ }^{47}$ F. Safford, "Bolívar, el estadista triunfante y el demócrata frustrado: los orígenes de la polarización partidista en Colombia", Anuario Colombiano de Historia Social y de la Cultura 31 (2004): 119-157.

${ }^{48}$ R. Jaramillo, Colombia: La modernidad postergada (Bogotá D.C: Argumentos), 1998.

${ }^{49}$ No debemos olvidar que la Corona española decidió erradicar de forma violenta las primeras células protestantes en Sevilla y Valladolid. En 1559 prohibió la importación de libros del extranjero, censurando muchos más e impidiendo a estudiantes españoles formarse en el exterior. Jaramillo, Colombia: La modernidad postergada..., 231.

${ }^{50}$ F. Guillén, El poder político en Colombia (Bogotá: Planeta, 1999).
} 
cómo los niños de los siglos XVIII, XIX y buena parte del XX, fueron educados con el catecismo del padre Gastón Astete, publicado en 1599, en el cual:

Tras su forma simple de preguntar y responder, tras su apariencia "racional", se oculta la intolerancia y su forma 'decisionista' de pensamiento ("sí o no como Cristo nos enseña', que impone naturalmente el sí y crea la noción de 'amigo-enemigo", popularizada luego en la 'asignatura' de "historia sagrada" con la frase de Cristo, "el que no está conmigo está contra mí". Todo lo cual llevó a Marcelino Menéndez y Pelayo a condenar la filosofía alemana, 'de los enemigos de nuestra raza', como a nuestros ilustres padres de la patria a condenar las enseñanzas del sensualismo de Bentham y Tracy a lo largo del siglo XIX ${ }^{51}$.

A este espíritu correspondieron no solo los pensadores conservadores de inicios de la República y la Universidad, sino también algunos pensadores liberales que recomendaron prudencia a la hora de enseñar los autores propuestos en los planes de estudio, como vimos figura en el artículo 229 del plan de estudios de Santander o como sucedería con la participación de los liberales en la Sociedad de Artesanos, a la que acudían a enseñar a leer, escribir y, posteriormente, predicar algunas ideas liberales. Después se arrepentirían una vez que el experimento terminara por fomentar la rebelión de sus miembros e imponiendo la presidencia de José María Obando, por lo cual terminarían en alianza con los sectores conservadores para derrocarlo ${ }^{52}$.

Uno de los rasgos más importantes de nuestra modernidad, desde sus inicios, es ese sincretismo profundo entre las actitudes premodernas hispánicas y las nuevas que trae consigo la ilustración. Si bien podemos encontrar este sincretismo en todo lugar del planeta al que llegaron de forma impuesta las nuevas actitudes, lo peculiar de la modernidad colombiana y en general latinoamericana, es la capacidad de camuflaje que ofrecen los nuevos discursos a las formas de conciencia precedentes. En las demandas de libertad, se perpetuó el autoritarismo; en la defensa de la tolerancia y la discusión pública, se encontró la censura y la exclusión, y en la liberación de las profesiones y su democratización se perpetuaron los privilegios. Respecto de la educación universitaria esto es evidente, pues es imposible no asombrarse del contraste que existe entre lo enunciado por la Ley de 1846, que plantea una auténtica revolución, y la realidad subsiguiente en la cual encontramos una prolongación de las ínfulas de prestigio personal y de exclusión de la gran mayoría en la educación superior. Al respecto comenta Fernando Guillén Martínez lo siguiente:

Agobiadas por la imposibilidad de crear una nobleza hereditaria (intento frustrado en España inicialmente y luego en América) las clases propietarias de la América Latina saludaron jubilosamente la aparición de una filosofía "ilustrada", producto de la agitación intelectual que culminó en la Revolución francesa, y adoptaron como sus banderas las de la libertad económica que estaba dando origen al auge del capitalismo burgués. La necesidad de expresar esa frustración y de encontrar una nueva vía de escape para sus impulsos internos de "honor" y de dominación (tanto objetiva como subjetivamente) creó un nuevo modo de opresión disfrazado con los ropajes exteriores y con el idioma de la democracia representativa y de la Revolución Industrial [...] Pero cuando todo parecía sonreír a los recién nacidos pueblos independientes, fue evidente que solamente habían "transferido" su angustia hacia otro objeto. Los dominadores ya no aspiraban a ser marqueses: deseaban ser doctores. Y renació la pugna por el enajenamiento, con verdadera furia ${ }^{53}$.

\footnotetext{
${ }^{51}$ R. Gutiérrez. Hispanoamérica: Imágenes y perspectivas (Bogotá D.C: Temis, 1989), 267-270.

${ }^{52} \mathrm{~F}$. Guillén, El poder político en Colombia.

${ }^{53}$ F. Guillén, Estructura histórica, social y política de Colombia (Bogotá D.C: Ariel, 2017), 159.
} 
El autor continúa comentando cómo el título de Doctor ya tenía cierto prestigio en España colonial, y cómo se transfiere a las nuevas repúblicas mediante la prolongación de ciertas expectativas sociales incrustadas en estructuras psicológicas. De ello se deriva cómo en Colombia, bajo esa aparente defensa de la educación y la ampliación de su oferta con carácter moderno y secular, se perpetúan las formas del título nobiliario y cómo las grandes consignas en la materia se contradicen con los hechos en términos de decisiones efectivas de gobierno ${ }^{54}$. De igual forma, vimos cómo todas las reformas fracasaron, quedándose en el papel, o también cómo a pesar de enfocar los esfuerzos de fomentar el estudio de ciencias útiles solo prosperaron aquellas profesiones - el derecho y la teología - que sirvieron a sus egresados para conseguir puestos burocráticos o un lugar en la actividad más lucrativa en el país: La política. Como afirmó Fernando Guillén Martínez:

La educación tiene en Colombia y tuvo siempre en la América Española un carácter de privilegio que debía ser defendido contra los asaltos de la muchedumbre. Los "patrones" la reclamaron siempre como don exclusivo para sus hijos y cuando el pueblo logró obtenerla, adquirió de manera automática una solidaridad ciega con la clase explotadora a la cual creía haber ingresado por ese mero hecho. Toda suerte de estorbos prácticos se colocaron contra el acceso de los grupos sociales pobres a los institutos de enseñanza, pero cuando algún afortunado logró sobrepasarlos, volvió su propio desdén contra las filas de la clase de la cual salió y se convirtió, a su turno, en un celoso defensor de la "exclusividad" cultural para unos cuantos escogidos. Como ejemplo característico podría citarse el de Marco Fidel Suárez, hijo natural de una lavandera antioqueña, educado por la protección de benignos eclesiásticos y más tarde Presidente de Colombia, defensor constante de las clases "conservadoras" privilegiadas y su aliado, a pesar de haber sido siempre explotado por ellas, de haber muerto pobre y de deberles su ruina política en el final de su vida. El señor Suárez, eminente escritor político y notable gramático, es un caso impresionante de "doctorado" impenitente"

Todo esto llama la atención y explica el fracaso de la fundación de la República, la cual tuvo por pilares a la institución de una Universidad pública. Los distintos momentos de la institución universitaria nos confirman esta paradoja de nuestra modernidad y nos hablan, no solo de la postergación de la experiencia de la misma, sino también de la situación actual de la Universidad pública en nuestro país, con una precaria financiación, graduando "doctores al vapor" 56 para poder sostenerse en los rankings a pesar de un presupuesto público deficiente, y a la espera de un cambio de la clase política que rige el país para que surja una nueva propuesta de reforma a la educación superior, que garantice su estabilidad, crecimiento y contribuciones científicas a la nación.

\footnotetext{
${ }^{54}$ Cabe recordar que dentro de las obligaciones que Santander impuso a la institución universitaria, una de ellas era dedicar un tiempo excesivo para evaluar a los estudiantes de la universidad, todo lo cual podría llevar hasta 22 horas para examinar a tan solo 12 estudiantes. De lo cual se comprende que el mismo presidente no contemplaba que se admitieran demasiados educandos en el claustro. Además, su decisión inicial de admitir solo aquellas universidades que estuvieran en Bogotá, Quito y Caracas, con la consecuente exclusión de colegios departamentales, implicaba cierto ideal parroquial que no contemplaba la existencia de universidades más allá de las "grandes" capitales. Lane, La reforma universitaria....

${ }^{55}$ F. Guillén, Estructura histórica, social y política de Colombia (Bogotá D.C: Ariel, 2017), 161.

${ }^{56}$ Así se decía de la Universidad Central que graduaba muchos doctores en Derecho y Teología en poco tiempo, a toda velocidad como una máquina de vapor.
} 


\section{Referencias}

Aguilera, M. Comp. Universidad Nacional de Colombia: génesis y reconstitución. Bogotá: Universidad Nacional de Colombia, 2001.

Ahern, E. "El Desarrollo de la Educación en Colombia". Acceso el 27 de enero de 2014. http://www.pedagogica.edu.co/storage/rce/articulos/rce22-23_04arti.pdf

Antolínez, R. "La filosofía del siglo XVIII. Novatores e ilustrados". En La filosofía en América Latina, G. Marquínez, 115-119. Bogotá D.C: El Búho, 1993.

Bushnell, D. El régimen de Santander en la Gran Colombia. Bogotá D.C: Tercer Mundo, 1966.

Cobo, J. M. La enseñanza superior en el mundo: Estudio comparado e hipótesis. España: Narcea, 1979.

López, L. H. Obra educativa: La querella benthamista 1748-1832. Bogotá D.C: Fundación Francisco de Paula Santander, 1993.

González, F. Educación y Estado en la historia de Colombia. Bogotá D.C: CINEP, 1970.

Guillén, F. El poder político en Colombia. Bogotá: Planeta, 1999. . Estructura histórica, social y política de Colombia. Bogotá D.C: Ariel, 2017.

Gutiérrez, R. Hispanoamérica: Imágenes y perspectivas. Bogotá D.C: Temis, 1989.

Jaramillo, J. "Esquema histórico de la Universidad colombiana". En La personalidad histórica de Colombia y otros ensayos, J. Uribe, 237-270. Bogotá: Instituto colombiano de cultura, 1977.

Jaramillo, R. Colombia: La modernidad postergada. Bogotá D.C: Argumentos, 1998.

Lane, J. La reforma universitaria de la Nueva Granada: 1820-1850. Bogotá D.C: Instituto Caro y Cuervo, 1994.

Ocampo, J. "Los orígenes oficiales de las universidades republicanas en la Gran Colombia 1826-1830". Revista de Historia de la Educación Colombiana 3 y 4 (2011): 27-44.

Quesada, G. A. "Los movimientos sociales anteriores a la Independencia. Motines, protestas, rebeliones e insurrecciones en la América Española durante el siglo XVIII”. En 1810: Antecedentes, desarrollo y consecuencias, M. Jaramillo, 97-150. Bogotá D.C: Taurus, 2010.

Reyes, C. J. "Los movimientos revolucionarios del siglo XVIII y su influencia libertaria". En 1810: Antecedentes, desarrollo y consecuencias, J. Mario, 53-93. Bogotá D.C: Taurus, 2010. 
Safford, F. "Bolívar, el estadista triunfante y el demócrata frustrado: los orígenes de la polarización partidista en Colombia". Anuario Colombiano de Historia Social y de la Cultura 31 (2004): 119-157.

Soto, D. "Aproximación histórica a la universidad colombiana". Historia de la Educación Latinoamericana 7 (2005): 101-138.

Universidad Nacional de Medellín. "Reseña histórica de la Universidad Nacional de Colombia Sede Medellín". Acceso el 10 de junio de 2020. https://docplayer.es/5773073-Resena-historica-de-la-universidad-nacional-decolombia-sede-medellin-oficina-de-planeacion.html

Zambrano, L. A. "Universidad, sujeto y radicalismo liberal colombiano: El régimen de gobierno de la moral de los sujetos". Educere. Investigación arbitrada 14, n. ${ }^{\circ} 49$ (2010): 381-394. 